\title{
CASE REPORT OPEN The challenge of objective confirmation of asthma diagnosis in primary care
}

\author{
Jatin Kaicker ${ }^{1}$, Wilfred Dang ${ }^{2}$ and Anthony D'Urzo ${ }^{3,4}$
}

Asthma represents one of the most common chronic conditions encountered in primary care and diagnosis should be confirmed objectively with the demonstration of variable airflow obstruction. As many asthmatics have normal lung function at the time of clinical presentation, objective confirmation of airflow limitation may be challenging. Fluctuations in airflow obstruction can be documented with simple office spirometry after bronchodilator challenge, home monitoring of peak expiratory flow and bronchoconstriction induced by spasmogens such as methacholine. We present a case highlighting the challenge of objective confirmation of asthma diagnosis in primary care and provide a critical review of the diagnostic approaches highlighted above. Our aim is to provide a pragmatic interpretation of the available literature with a view to assisting clinicians in selecting the diagnostic test best suited for individualised patient encounters.

npj Primary Care Respiratory Medicine (2014) 24, 14032; doi:10.1038/npjpcrm.2014.32; published online 24 July 2014

\section{CASE PRESENTATION}

A 48-year-old woman with no smoking history reported cough and feeling short of breath with exertion beginning several months before her clinic visit. It was not clear whether she experienced any episodes of wheezing or chest tightness in association with her shortness of breath. She also reported longstanding nasal congestion and throat irritation, which are symptoms consistent with postnasal drip syndrome. She did not complain of chest pain or respiratory symptoms associated with nocturnal or early-morning awakening.'

Her past medical history included eczema and a single episode of generalised hives. She reported sensitivities to trimethoprim and sulfamethoxazole as well as to metronidazole. Skin prick testing revealed positive responses to house dust mites. There was no family history of atopy or asthma. She did not report a history of cardiovascular illness. On physical examination, the blood pressure was 130/90 bilaterally, heart rate was 76 beats/min and regular, with a respiratory rate of 10 breaths/min. Her body mass index was $32 \mathrm{~kg} / \mathrm{m}^{2}$. Air entry was equal bilaterally with no audible wheeze. There was mild nasal mucosal oedema and erythema without evidence of nasal polyps. Simple spirometry was carried out in the clinic for further assessment according to the American Thoracic Society Criteria. ${ }^{2}$ A chest X-ray and 12-lead electrocardiogram obtained at the initial visit were both normal.

\section{INTRODUCTION}

Asthma is a complex disease associated with airway inflammation, hyper-responsiveness and variable airflow obstruction that may not all co-exist in many patients. ${ }^{1}$ The criteria for spirometric diagnosis of asthma include an improvement in forced expiratory volume in $1 \mathrm{~s}\left(\mathrm{FEV}_{1}\right)$ of $12 \%$ and $200 \mathrm{ml}$ after bronchodilator challenge. ${ }^{1}$ This latter approach is often recommended as a firstline strategy for asthma diagnosis in the asthma guidelines. ${ }^{1}$
Simple spirometry can be carried out in the physician's office in a timely manner, and it provides useful information about the relationship between flow and volume. There are few clinically relevant risks associated with performing simple spirometry tests. However, the test's accuracy and reproducibility depends on maximal effort by the patient. The assessor must have the expertise to coach the patient, address language barriers and recognise unacceptable efforts, as poorly performed manoeuvres can mimic various disease patterns., ${ }^{3,4}$ Measurement of peak expiratory flow rate (PEFR) is simple, convenient and can be done either in the clinic or in the home settings. ${ }^{1}$ PEFR variability has been linked to airway hyper-reactivity and is recognised as a useful diagnostic aid that is well suited for adoption in primary care. $^{1}$

More sophisticated testing such as methacholine challenge is recommended among patients who present with clinical features compatible with asthma but normal spirometric findings on initial testing. Methacholine challenge testing (MCT) includes inhalation of methacholine, a substance that is intended to induce bronchoconstriction in susceptible airways and may be associated with some risks. To our knowledge, there have been no reported deaths from MCT. ${ }^{5}$ Some reports indicate that MCT is quite safe, even in patients with severe obstruction. ${ }^{6}$ To date, the role of MCT as a first-line test for asthma diagnosis in the primary care setting has not been clearly delineated and has yet to be recommended by any agency or guideline outside of a specialty care facility.

The importance of objective confirmation of asthma diagnosis in the community setting has been discussed by Aaron et al. ${ }^{7}$ They describe that about one-third of obese and non-obese individuals with physician-diagnosed asthma did not have asthma when objectively assessed. These findings raise awareness of the importance of objective confirmation of asthma diagnosis, and have stimulated considerable debate around which test to consider first by primary care physicians in the office setting. ${ }^{8,9}$

${ }^{1}$ Michael G Degroote School of Medicine, McMaster University, Hamilton, Ontario, Canada; ${ }^{2}$ University of Ottawa's School of Medicine, Ottawa, Ontario, Canada; ${ }^{3}$ Primary Care Respiratory Alliance of Canada (PCRC), Toronto, Ontario, Canada and ${ }^{4}$ Department of Family and Community Medicine, University of Toronto, Toronto, Ontario, Canada. Correspondence: A D'Urzo (tonydurzo@sympatico.ca)

Received 13 September 2013; revised 13 January 2014; accepted 21 January 2014 
Table 1. Initial spirometry assessment: spirometry performed during the initial clinic visit

\begin{tabular}{lcccccc}
\hline \multirow{2}{*}{ Spirometry indices } & \multicolumn{2}{c}{ PRE } & & \multicolumn{2}{c}{ POST } & \multirow{2}{*}{ \% Change } \\
\cline { 2 - 3 } \cline { 5 - 6 } & Best & $\%$ Pred & & Best & $\%$ Pred & \\
\hline FVC & 3.8 & 98 & & 3.82 & 99 & 1 \\
FEV $_{1}$ & 2.85 & 91 & & 2.96 & 95 & 4 \\
FEV $_{1} /$ FVC & 0.75 & & & 0.77 & & \\
\hline
\end{tabular}

Abbreviations: $\mathrm{FEV}_{1}$, forced expiratory volume in $1 \mathrm{~s} ; \mathrm{FVC}$, forced vital capacity; \% Pred, \% predicted.

\section{CASE UPDATE}

Spirometry performed during the initial clinic visit revealed a prebronchodilator forced vital capacity (FVC) of 3.80 I (98\% predicted), $\mathrm{FEV}_{1}$ of $2.85 \mathrm{I}$ ( $91 \%$ predicted) and $\mathrm{FEV}_{1} / \mathrm{FVC}$ ratio of 0.75 . The results are shown in Table 1. After bronchodilator challenge with salbutamol, the FVC was 3.82 I ( $99 \%$ predicted) and $\mathrm{FEV}_{1}$ was 2.96 I (95\% predicted), with an improvement of $4 \%$ and $110 \mathrm{ml}$ from baseline. The $\mathrm{FEV}_{1} / \mathrm{FVC}$ ratio was 0.77 (Table 1). After discussion about the possible causes of her symptoms, including asthma, a management plan including watchful waiting of her mild symptoms was decided upon, including repeat spirometry during a follow-up visit in 1 month's time or sooner to evaluate interval change in clinical status.

The patient did not return until 6 months after the initial clinic visit. Spirometry revealed a pre-bronchodilator FVC of 4.13 I (105\% predicted), $\mathrm{FEV}_{1}$ of 3.02 I ( $97 \%$ predicted) and $\mathrm{FEV}_{1} / \mathrm{FVC}$ ratio of 0.75 (Table 2) After bronchodilator challenge with salbutamol, the FVC was 4.13 I (107\% predicted), $\mathrm{FEV}_{1}$ was 3.00 I (95\% predicted; with an improvement of $0 \%$ and reduction of $20 \mathrm{ml}$ from baseline), and the $\mathrm{FEV}_{1} / \mathrm{FVC}$ ratio was 0.73 (Table 2). Since her previous clinic visit, she described her symptoms as somewhat worse with increased cough, mucus production and shortness of breath with activity. Salbutamol was prescribed for as-needed use and an MCT was ordered. The results of baseline spirometry conducted $\sim 2$ months later and just before $\mathrm{MCT}$ and after reversal of methacholine-induced bronchoconstriction are shown in Table 3. Although baseline spirometry was normal and comparable to the previous measurements, mentioned above, the provocative concentration of methacholine resulting in a $20 \%$ reduction in $\mathrm{FEV}_{1}$ (PC20) from baseline was $3.37 \mathrm{mg} / \mathrm{ml}$, a finding that would support a positive hyper-bronchial test. Treatment with regular inhaled corticosteroid and as-needed salbutamol resulted in a marked improvement in symptoms.

\section{CLINICAL CONSIDERATIONS}

In this case, several attempts with simple spirometry failed to identify $\mathrm{FEV}_{1}$ changes that would meet the bronchodilator reversibility criteria for asthma diagnosis outlined in national and international guidelines. ${ }^{1,10}$ Lusardi et al. ${ }^{11}$ reveal that most patients in primary care have mild asthma and well-preserved lung function and that airflow obstruction-defined as a reduction in the ratio of $\mathrm{FEV}_{1} / \mathrm{FVC}<0.70$-was observed in only $21 \%$ of patients diagnosed with asthma. They were not able to demonstrate a significant advantage of office spirometry in improving the diagnosis of asthma and COPD in standard general practice. ${ }^{11}$

Goldstein et al. ${ }^{12}$ were among the first to report that variability in PEFR and postbronchodilator $\mathrm{FEV}_{1}$ responses are poor substitutes for methacholine inhalation challenge in the assessment of patients with suspected asthma with normal findings on lung examination, chest radiography and spirometry. The reports
Table 2. Follow-up spirometry assessment

\begin{tabular}{|c|c|c|c|c|c|}
\hline \multirow[t]{2}{*}{ Spirometry indices } & \multicolumn{2}{|c|}{ Pre } & \multicolumn{2}{|c|}{ Post } & \multirow[t]{2}{*}{$\%$ Change } \\
\hline & Best & $\%$ Pred & Best & $\%$ Pred & \\
\hline FVC & 4.04 & 105 & 4.13 & 107 & 2 \\
\hline $\mathrm{FEV}_{1}$ & 3.02 & 97 & 3.00 & 96 & 0 \\
\hline $\mathrm{FEV}_{1} / \mathrm{FVC}$ & 0.75 & & 0.73 & & \\
\hline
\end{tabular}

Spirometry performed six months after the initial clinic visit. Abbreviations: FEV 1 , forced expiratory volume in $1 \mathrm{~s}$; FVC, forced vital capacity; \% Pred, \% predicted.
Table 3. Methacholine challenge test

\begin{tabular}{lcccc}
\hline $\begin{array}{l}\text { Methacholine concentration } \\
(\mathrm{mg} / \mathrm{ml})\end{array}$ & $\begin{array}{c}F V C \\
(\mathrm{l})\end{array}$ & $\begin{array}{c}F V C \\
(\% \mathrm{Ctrl})\end{array}$ & $\begin{array}{c}\mathrm{FEV}_{1} \\
(\mathrm{l})\end{array}$ & $\begin{array}{c}\mathrm{FEV}_{1} \\
(\% \mathrm{Ctrl})\end{array}$ \\
\hline Baseline & 3.85 & 96 & 2.98 & 97 \\
Control (Ctrl) & 4.01 & 100 & 3.06 & 100 \\
0.125 & 3.23 & 81 & 3.04 & 99 \\
0.500 & 3.10 & 77 & 2.91 & 95 \\
2.000 & 3.25 & 81 & 2.77 & 91 \\
4.000 & 3.17 & 79 & 2.3 & 75 \\
Reversal & 3.68 & 92 & 2.8 & 92 \\
\hline
\end{tabular}

Baseline spirometry prior to methacholine challenge test and after reversal of methacholine-induced bronchoconstriction.

$\mathrm{PC} 20\left(\mathrm{FEV}_{1}\right)=3.37 \mathrm{mg} / \mathrm{ml}$, where $\mathrm{PC} 20$ is the provocative concentration of methacholine resulting in a $20 \%$ reduction in $\mathrm{FEV}_{1}$ from baseline.

Abbreviations: $\mathrm{FEV}_{1}$, forced expiratory volume in $1 \mathrm{~s}$ (predicted value $=3.11 \mathrm{l})$; FVC, forced vital capacity (predicted value $=3.85 \mathrm{l}$ ); \% Pred, $\%$ predicted.

of Hunter et al. ${ }^{13}$ indicate that methacholine responsiveness is more than twice as sensitive as bronchodilator reversibility for $\mathrm{FEV}_{1}$ and variability in PEFR as a marker of mild asthma. Furthermore, Schneider et al. ${ }^{14}$ highlight that the sensitivity for diagnosing airway obstruction in asthma with simple spirometry was only $29 \%$. The data described by Ulrik et al. ${ }^{15}$ suggest that airway responsiveness to histamine, diurnal peak-flow variability and bronchodilator reversibility cannot be used interchangeably as objective markers of asthma in epidemiologic studies. They suggest on the basis of their findings that airway hyperresponsiveness to a nonspecific bronchoconstrictor is recommended as the objective marker of asthma-related airway lability. Yurdakul et $a .^{16}$ also describe a much higher sensitivity for MCT compared with FEV $_{1}$ reversibility and PEFR variability for asthma diagnosis among patients attending an outpatient asthma clinic. Furthermore, the data described by Aaron et al. ${ }^{7}$ suggest that asthma diagnosis could be confirmed in only $16 \%$ of patients by means of postbronchodilator spirometry at the time of testing (at least $15 \%$ and at least $200 \mathrm{ml}$ ) and in $72 \%$ of patients by means of bronchial challenge testing with methacholine. Finally, Luks et al. ${ }^{17}$ suggest that only $10.8 \%$ of patients were diagnosed with asthma using simple pre- and postbronchodilator spirometry at the time of testing, while MCT resulted in a confirmation rate of $61.7 \%$ and an exclusion rate of $27.3 \%$ among individuals whose lung function was reported to be in the normal range at clinical presentation. It is important to note that, among asthma patients identified in an administrative database with lower lung function compared with the studies cited above, Macy et al. ${ }^{18}$ found that $62 \%$ of asthmatics were identified with $\mathrm{FEV}_{1}$ reversibility. 
These findings ${ }^{18}$ may suggest that baseline lung function and asthma control in general may influence bronchodilator responsiveness.

The findings highlighted above underscore the lower sensitivity of bronchodilator reversibility and PEFR variability as confirmatory tests compared with MCT for asthma diagnosis in primary care among patients with mild disease. Repeated testing with simple spirometry at different visits is advised in order to obtain objective confirmation of asthma diagnosis. ${ }^{19}$ To date, there are no studies describing how many simple spirometric tests or trials of PEFR monitoring would be required to demonstrate bronchodilator responsiveness and airflow variability in a given patient in whom asthma is suspected. Guidelines do not clearly highlight how bronchodilator reversibility and PEFR variability testing might be implemented in primary care, including how patients with normal lung function on repeat testing should be managed during the interval between clinical suspicion of asthma and objective confirmation, particularly as treatment might reduce the odds of detecting meaningful improvements in $\mathrm{FEV}_{1}$ after bronchodilator challenge or documentation of PEFR variability. Although MCT is safe and perhaps the most sensitive test for diagnosis of mild asthma, its role as a first-line test in primary care remains to be determined and it is not without deficiencies as a confirmatory test. For example, a provocative concentration of methacholine causing a $20 \%$ fall in $\mathrm{FEV}_{1}$ of $<8 \mathrm{mg} / \mathrm{ml}$ may lack specificity and sensitivity. ${ }^{20}$ False-positive results are seen in patients with other diseases, including COPD, allergic rhinitis and sarcoidosis. Because MCT has a high negative predictive value, it is more useful in ruling out asthma (if the result is negative) than in ruling it in (if the result is positive). A negative methacholine challenge test nearly always rules out asthma; however, a positive test result needs to be interpreted cautiously if the patient is not experiencing symptoms. ${ }^{21-23}$

\section{SUMMARY AND CONCLUSIONS}

The case presented here and the series of studies highlighted above underscore the challenge of asthma diagnosis in primary care where there is a high probability of normal lung function at the time of testing in many patients. This clinical scenario calls for more studies dealing with the evaluation of asthma diagnostic and management strategies that are pragmatic, sensitive and cost-effective. Understanding the benefits and limitations of reversibility testing, PEFR variability measurements and MCT may help primary care physicians to better tailor their diagnostic approach among individuals with suspected asthma.

\section{CONTRIBUTIONS}

All authors contributed to the development of this article.

\section{COMPETING INTERESTS}

The authors declare no conflict of interest. $A D$ is an Associate editor of npj Primary Care Respiratory Medicine, but was not involved in the editorial review of, nor the decision to publish, this article.

\section{FUNDING}

The authors declare that no funding was received.

\section{REFERENCES}

1 Lougheed MD, Lemiere C, Ducharme FM, Licskai C, Dell SD, Rowe BH et al. Canadian Thoracic Society 2012 guideline update: diagnosis and management of asthma in preschoolers, children and adults. Can Respir J 2012; 19: 127-164.

2 Miller MR, Hankinson J, Brusasco V, Burgos F, Casaburi R, Coates A et al. ATS/ERS Task Force: standardisation of lung function testing. Eur Respir J 2005; 26: 319-338.

3 Crenesse D, Berlioz M, Bourrier T, Albertini M. Spirometry in children aged 3 to 5 years: reliability of forced expiratory maneuvers. Pediatr Pulmonol 2001; 32: 56-61.

4 Enright PL. The use and abuse of office spirometry. Prim Care Respir J 2008; 17: 238-242.

5 Crapo RO, Casaburi R, Coates AL, Enright PL, Hankinson JL, Irvin CG et al. Guideline for methacoline and exercise challenge testing 1999. The Official Statement of the American Thoracic Society was adopted by the ATS Board of Directors, July 1999. Am J Respir Crit Care Med 2000; 161: 309-329.

6 Martin RJ, Wanger JS, Irvin CG, Bucher Bartelson B, Cherniack RM, Asthma Clinical Research Network (ACRN). Methacholine challenge testing: safety of low starting FEV 1 . Chest 1997; 112: 53-56.

7 Aaron SD, Vandernheen KL, Boulet LP, Mclvor RA, FitzGerald JM, Hernandez P et al. Overdiagnosis of asthma in obese and nonobese adults. CMAJ 2008; 179: 1121-1131.

8 D'Urzo AD. Must family physicians use spirometry in managing asthma patients? No. Can Fam Physician 2010; 56: 127-129.

9 Kaplan A, Stanbrook M. Must family physicians use spirometry in managing asthma patients? Yes. Can Fam Physician 2010; 56: 126-128.

10 Pellegrino R, Viegi G, Brusasco V, Crapo RO, Burgos F, Casaburi R et al. Interpretative strategies for lung function tests. Eur Respir J 2005; 26: 948-968.

11 Lusardi M, De Benedetto F, Paggiaro P, Sanguinetti CM, Brazzola G, Ferri P et al. A randomized controlled trial on office spirometry in asthma and COPD in standard general practice: data from spirometry in asthma and COPD: a comparative evaluation Italian study. Chest 2006; 129: 844-852.

12 Goldstein MF, Veza BA, Dunsky EH, Dvorin DJ, Belecanech GA, Haralabatos IC. Comparisons of peak diurnal expiratory flow variation, postbronchodilator FEV(1) responses, and methacholine inhalation challenges in the evaluation of suspected asthma. Chest 2001; 119: 1001-1010.

13 Hunter CJ, Brightling EC, Woltmann G, Wardlaw AJ, Pavord ID. A comparison of the validity of different diagnostic tests in adults with asthma. Chest 2002; 121: 1051-1057.

14 Schneider A, Gindner L, Tilemann L, Schermer T, Dinant GJ, Meyer FJ et al. Diagnostic accuracy of spirometry in primary care. BMC Pulm Med 2009; 9: 31.

15 Ulrik JS, Postma DS, Vibeke Backer V. Recognition of asthma in adolescents and young adults: which objective measure is best? J Asthma 2005; 42: 549-554.

16 Yurdakul AS, Dursun B, Canbakan S, Cakaloglu A, Capan N. The assessment of validity of different asthma diagnostic tools in adults. J Asthma 2005; 42: 843-846.

17 Luks VP, Vandemheen KL, Aaron SD. Confirmation of asthma in an era of over diagnosis. Eur Respir J 2010; 36: 255-260.

18 Macy E, Schatz M, Gibbons C, Zeiger R. The prevalence of reversible airflow obstruction and/or methacholine hyperreactivity in random adult asthma patients identified by administrative data. J Asthma 2005; 42: 213-220.

19 Global Strategy for Asthma Management and Prevention (GINA), 2012. http:// www.ginasthma.org/documents/4. Accessed 4 August 2013.

20 Contoli M, Papi A. When asthma diagnosis becomes a challenge. Eur Respir J 2010; 36: 231-233.

21 Gilbert R, Auchincloss JH. Post-test probability of asthma following methacholine challenge. Chest 1990; 97: 562-565.

22 Perpina M, Pellicer C, de Diego A, Compte L, Macian V. Diagnostic value of the bronchial provocation test with methacholine in asthma: a Bayesian analysis approach. Chest 1993; 104: 149-154.

23 Davies BE, Cockcroft DW. Past, present and future uses of methacholine testing. Expert Rev Respir Med 2012; 6: 321-329.

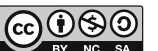

This work is licensed under a Creative Commons AttributionNonCommercial-ShareAlike 4.0 International License. The images or other third party material in this article are included in the article's Creative Commons license, unless indicated otherwise in the credit line; if the material is not included under the Creative Commons license, users will need to obtain permission from the license holder to reproduce the material. To view a copy of this license, visit http:// creativecommons.org/licenses/by-nc-sa/4.0/ 